\title{
Ribavirin Baskılanmış Polimer Temelli Ribavirin-Seçici Potansiyometrik PVC- Membran Mikrosensör Geliştirilmesi
}

\author{
Murat YOLCU ${ }^{1 *}$, Zuhal YOLCU ${ }^{1}$, Saim TOPÇU ${ }^{1}$, Nihal YARDIM ÇELIK ${ }^{1}$ \\ ${ }^{1}$ Giresun Üniversitesi, Fen Edebiyat Fakültesi, Kimya Bölümü, Giresun, Türkiye
}

Geliş Tarihi: 24.10 .2017

"Sorumlu Yazar: murat.yolcu@ giresun.edu.tr

Kabul Tarihi: 27.11.2017

Özet

$\mathrm{Bu}$ çalışmada antiviral bir ilaç etken madde olan ribavirinin moleküler baskılanmış polimeri (MIP) süspansiyon polimerizasyonu ile sentezlenmiş ve bu polimer ile ribavirin seçici potansiyometrik mikrosensör hazırlanmıştır. Hazırlanan mikrosensörün potansiyometrik performansları araştırılmıştır. En iyi potansiyometrik performans özelliklerini \% 4 MIP, \% 67 nitrofeniloktileter, \% 29 polivinilklorür bileşimine sahip sensörün sergilediği belirlendi. Bu sensörün doğrusal çalışma aralığ $1 \times 10^{-5}-1 \times 10^{-2} \mathrm{M}, 10$ katlık konsantrasyon değişimindeki $\mathrm{mV}$ farkı 29,8 , tayin limiti $8,7 \times 10^{-6} \mathrm{M}$, cevap zamanı 10 s olarak belirlendi. Geliştirilen ribavirin seçici mikrosensör kullanılarak bazı ticari ilaçlarda ribavirin tayinleri başarıyla gerçekleştirilmiştir.

Anahtar Kelimeler: Moleküler baskılama, Ribavirin, İyon seçici sensör, Potansiyometri.

\section{Development of a Ribavirin Selective Potentiometric PVC-Membrane Microsensor based on Ribavirin Imprinted Polymer}

\begin{abstract}
In this study, a molecularly imprinted polymer (MIP) of ribavirin, which is an antiviral active drug, was synthesized by suspension polymerization and on the basis of the synthesized polymer, ribavirin selective potentiometric microsensor was constructed. Potentiometric performance characteristics of the microsensor was investigated. It was determined that the sensor membrane at the ratio of $4 \%$ MIP, $67 \%$ nitrophenyloctylether and $29 \%$ polyvinyl chloride performed the best potentiometric performance characteristics. For this sensor; linear range, slope, detection limit and response time were determined as $1 \times 10^{-5}-1.0 \times 10^{-2} \mathrm{M}, 29.8 \mathrm{mV} /$ decade, $8,7 \times 10^{-6} \mathrm{M}$, and $\sim 10 \mathrm{~s}$, respectively. Potentiometric determinations of ribavirin in commercial drug samples were successfully performed by using ribavirin selective microsensor.
\end{abstract}

Keywords: Molecular imprinting, Ribavirin, Ion selective sensor, Potentiometry. 


\section{Giriş}

Ribavirin (Şekil 1.) antiviral bir ilaç etken maddedir. Bazı DNA ve RNA virüslerine karşı sahip olduğu geniş spektrum aktivitesi sayesinde oldukça etkilidir. RNA polimeraz faaliyetini inhibe eder yani viral genetik materyalin kopyalanması sürecine müdahale eder. Ribavirin plazma proteinlerine bağlanmayan hidrofilik bir moleküldür. Yakın zamana kadar astım rahatsızlığına yol açan solunum sinsityal viral enfeksiyonların tedavisinde kullanılırken, günümüzde çoğunlukla hepatit $\mathrm{C}$ tedavisinde interferon ilaçlarıyla beraber kullanılmaktadır (Scott ve Perry, 2002).

Günümüzde ilaç etken madde tayinleri genellikle maliyeti yüksek yöntemlerle gerçekleştirilmektedir. Ribavirinin biyolojik ve klinik numunelerdeki analizleri kromatografi (Zironi ve ark. 2011; Lijke ve ark. 2012), spektrofluorimetri (Alarfaj ve El-Toh, 2012), kapiler elektroforez (Breadmore ve ark. 2004) gibi yöntemlerle yapılabilmektedir. İyon seçici elektrotların kullanıldığı potansiyometrik metotlar daha pahalı tayin yöntemlerine alternatif olarak son yıllarda çoğu tayinlerde sıklıkla kullanılmaktadır. Potansiyometrik sensörlerin yapımında çok farklı kimyasal özelliklere sahip analite özgü seçici maddeler kullanılmaktadır (Bochenska, 1998). Seçiciliği sağlayan materyaller olarak moleküler baskılanmış polimerler (MIP) de sıklıkla kullanılmaktadır. Baskılama sonucu oluşan kalıp, baskılanan türe (iyona veya molekül) özgüdür. Bundan dolayı polimer matriks, baskılanan türün de içinde olduğu bir karışımda ilgili türe karş1 \% 100’e yakın oranda seçici davranmaktadır (Karabörk, 2007; Yolcu, 2011). MIP'lerin seçici materyaller olarak kullanılmasıyla ilaç etken madde özelliği sergileyen çok sayıda moleküle seçici elektrot geliştirilmiştir (Javanbakht ve ark 2008; Yarman ve Scheller, 2014). Literatürde ribavirin molekülünün baskılanması üzerine çalışmalara rastlamak mümkündür. Örneğin; ribavirinin seçici olarak tanınması amacıyla çok duvarlı karbon nanotüplerin yüzeyinde ribavirin baskılanmış polimerler geliştirilmiştir (Xu ve ark. 2012). Grafen oksit ile takviye edilmiş ve metakrilik asit fonksiyonel monomerinin kullanıldığı ribavirin baskılanmış polimerin kullanılması ile hazırlanan ribavirin seçici PVC membran elektrot geliştirilmesi üzerine çok yakın zamanda bir çalışma yapılmıştır (Jian-Wen ve ark, 2017).

$\mathrm{Bu}$ çalışmada, 1-vinilimidazol fonksiyonel monomeri, etilenglikoldimetakrilat (EGDMA) çapraz bağlayıcı, benzoil peroksit (BPO) polimer başlatıcısı kullanılarak ribavirinin moleküler baskılanmış polimerinin sentezlenmesi, bu polimerin seçici materyal (iyonofor) olarak kullanımıyla ribavirin-seçici PVC membran potansiyometrik mikrosensörün geliştirilerek performansının araştırılması ve ribavirin-seçici sensörün kullanılması ile bazı ticari ilaçların ribavirin içeriklerinin belirlenmesi amaçland. 


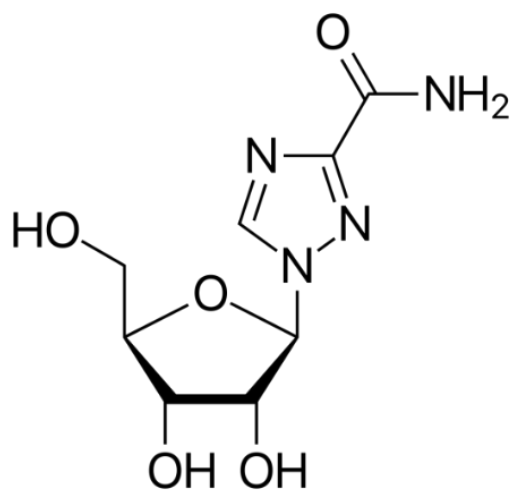

Şekil 1. Ribavirin (1- $\beta$-D-ribofuranosil-1, 2, 4-triazol-3-karboksamid)'in kimyasal yapısı.

\section{Materyal ve Metot}

\subsection{Materyal}

\section{Kimyasallar}

Etilenglikoldimetakrilat (EGDMA), benzoil peroksit (BPO), 1-vinilimidazol (1-viim), polivinilalkol (PVA), toluen, etanol, tetrahidrofuran (THF), yüksek molekül ağırlıklı polivinilklorür (PVC), o-nitrofeniloktileter (NPOE), dioktilsebakat (DOS) ve grafit Sigma-Aldrich firmasından, ribavirin Roche firmasından, epoksi reçinesi (Ultrapur SU 2227 Victor (Italy) firmasından, sertleştirici (Desmodur RFE ) Bayer AG firmasından, çalışmada kullanılan diğer tuzlar ve çözücüler Merck firmasindan temin edildi.

\section{Cihazlar}

Potansiyel ölçümleri, tasarımı ve yazılımı araştırma laboratuarımızda geliştirilen ve bilgisayar programı ile desteklenmiş çok kanallı potansiyometre cihazıyla gerçekleştirildi. Potansiyel ölçümlerinde referans elektrot olarak, Ag/AgCl elektrot (Basi-MF-2079-RE-5B) kullanıldı. Tartım işlemlerinde, Shimadzu (Model AUX220) analitik terazi kullanıldı. Çözeltilerin hazırlanmasında kullanılan deiyonize su Sartorius Stedim (Arium*611UV) marka deiyonize su cihazı ile temin edildi.

\section{Standart Çözeltilerin Hazırlanması}

Standart çözeltiler deiyonize su ile analitik saflıktaki stoktan konsantrasyonu 0,01 M olacak şekilde hazırlandı ve istenilen derişimlere seyreltildi.

\section{Ribavirin Baskılanmış Polimerin Sentezi}

Hedef molekül olarak ribavirin, fonksiyonel monomer olarak 1-vinilimidazol, çapraz bağlayıcı olarak etilenglikoldimetakrilat (EGDMA) ve polimer başlatıcısı olarak benzoil peroksitin kullanıldığı 
süspansiyon polimerizasyonu ile ribavirin molekülü baskılanmış polimer (MIP) sentezlendi. Bu amaçla; $500 \mathrm{mg}$ ribavirin $50 \mathrm{~mL}$ 'lik bir balona alınarak $30 \mathrm{~mL}$ deiyonize suda çözüldü. Ribavirin çözeltisi üzerine, $0,5 \mathrm{~mL}$ 1-vinilimidazol ilave edilip çözüldü. Çözelti karışımın üzerine $3 \mathrm{~mL}$ toluende çözülen 8 mL EGDMA ilave edildi. Elde edilen monomer karışımında 0,015 g benzoil peroksit çözüldükten sonra balonun ağzı septumla kapatıldı ve çözeltiden 15 dakika $\mathrm{N}_{2}$ gazı geçirildi. 50 mL'lik bir başka balonda, $50 \mathrm{mg}$ polivinil alkol (PVA), 12,5 mL deiyonize suda çözüldü ve çözeltiden 20 dakika $\mathrm{N}_{2}$ gazı geçirildi. PVA çözeltisi içeren balon, manyetik karıştırıcı üzerinde termostatik ayarlı yağ banyosunda $60{ }^{\circ} \mathrm{C}$ 'ye kadar 1sıtıld1. Daha sonra içerisine monomer karışımı ilave edilerek polimerleşmenin tamamlanması için $60^{\circ} \mathrm{C}$ 'de 24 saat bırakıldı. Beyaz renkli ribavirin baskılanmış polimerler elde edildi. Reaksiyona girmeyen monomerlerin uzaklaştırılması için polimerler etanol/su (50/50; v/v) karışımında yıkandı. Ayrıca MIP ile karşılaştırmak amacıyla yukarıdaki aynı sentez metodu kullanılarak ribavirin içermeyen baskılanmamış polimer (NIP) de hazırlandi.

\section{Polimerden Kalıp Molekülün Uzaklaştırılması}

Sentezlenen ribavirin baskılanmış polimerlerden ribavirinin uzaklaştırılması için, $50 \mathrm{mg}$ polimer $20 \mathrm{~mL}$ 0,5 M HCl çözeltisi ile çalkalayıcı kullanılarak 24 saat etkileştirildi. pH'sı nötral olan süzüntü elde edilene kadar polimerler deiyonize su ile yıkandı.

\section{Ribavirin Seçici Mikro Sensörün Hazırlanması}

Genel olarak sensörlerin hazırlanması iki aşamadan oluşmuştur (Isildak ve ark., 2004; Yolcu M, 2008). Katı kontak karışımının hazırlanması aşamasında; ağırlıkça \% 50 grafit, \% 35 epoksi reçinesi (Ultrapur SU 2227) ve \% 15 sertleştirici (Desmadur RFE) içeren karışım THF çözücüsü içerisinde 15-20 dakika karıştırıldı, uygun viskozite sağlandığında bir bakır tel (yaklaşık 0,4-0,5 mm çap, 0,1-0,2 mm uzunlukta metalik açıklık ve geri kalan 5-6 cm izole kablodan oluşan) bu karışıma 3-5 defa daldırılarak üzeri kaplandı ve 50-60 ${ }^{\circ} \mathrm{C}$ 'de bir gece beklemeye birakıldı. PVC membran kokteylinin hazırlandığı ikinci aşamada; ağırlıkça \% 4-8 MIP, \% 65-67 NPOE veya DOS, \% 27-29 PVC içeren karışımın THF çözücüsünde çözülmesiyle hazırlandı. Son olarak katı kontak yüzeyleri, yukarıda bileşimi verilen PVC-membran kokteyline 4-5 defa daldırılarak kaplandı ve oda şartlarında 3-4 saat kurumaya bırakıldı. Benzer işlemler MIP yerine NIP kullanılarak ta uygulandı.

\subsection{Metot}

Hazırlanan ribavirin-seçici sensörün potansiyometrik davranışları (doğrusal değişim aralıkları, cevap zamanları, kalibrasyon, pH çalışma aralı̆̆ı, tayin limitleri ve kullanım ömürleri v.b.) incelendi 
(IUPAC 1994). Günlük ölçümlerden önce; sensörler $10^{-3} \mathrm{~mol} / \mathrm{L}$ derişimindeki standart ribavirin çözeltilerinde 6 saat şartlandırıldı. Sensörler kullanımda oldukları zaman dilimi içerisinde kuru olarak veya deiyonize su içinde saklandı. Sensör ve referans elektrotun 5 mL' lik çözeltiye aynı derinlikte daldırılmasıyla, potansiyel ölçümleri gerçekleştirildi. Her ölçümden önce sensör ve referans elektrot deiyonize su ile yıkandı. Ölçümler çoğunlukla $10^{-2}-10^{-7}$ mol.L $\mathrm{L}^{-1}$ derişim aralığındaki standart çözeltilerde gerçekleştirildi.

\section{Bulgular ve Tartışma}

Öncelikle çok sayıda özdeş sensör hazırlandı. Özdeş sensörlerden en iyi performansı sergileyen sensör seçilerek potansiyometrik performans özellikleri test edildi. Hazırlanan sensörler için test edilen optimum membran bileşimleri ve bazı potansiyometrik performans özellikleri Tablo 1.'de verilmiştir. Tablo1. incelendiğinde RBV-1 sensörün diğerlerine göre daha iyi performans sergilediği görülmektedir. Tablonun en alt satırında verilen sensör; (Jian-Wen ve ark, 2017) MIP yapısı ve membran bileşimi farklı ve iç çözelti içeren klasik elektrot tipindedir. Ancak bu sensörün RBV-1 sensöre göre eğimi daha yüksek, tayin limiti daha düşük ve çalışma aralığı daha dardır. Cevap zamanı açısından çalışmamızda hazırladığımız RBV-1 sensör daha avantajlıdır. Ayrıca RBV-1 sensör bütünüyle katı yapıda olup minyatürizasyona uygundur. Bu yönleriyle geliştirilen RBV-1 sensörün avantajlı olduğu söylenebilir.

Tablo 1. Ribavirin-seçici sensörler için membran bileşimleri ve bazı performans özellikleri.

\begin{tabular}{|c|c|c|c|c|c|c|c|c|c|}
\hline \multicolumn{5}{|c|}{ Membran Bileşimi (\% Kütlece) } & \multicolumn{5}{|c|}{ Potansiyometrik Davranış } \\
\hline Sensör & MIP & PVC & NPOE & DOS & $\begin{array}{c}\text { mV Değişimi } \\
\text { (Eğim) }\end{array}$ & $\begin{array}{l}\text { Doğrusal Çalışma } \\
\text { Aralığ } 1(\mathrm{~mol} / \mathrm{L})\end{array}$ & $\begin{array}{l}\text { Tayin Limiti } \\
(\mathrm{mol} / \mathrm{L})\end{array}$ & $\begin{array}{c}\text { Cevap } \\
\text { zamanı }(\mathrm{s})\end{array}$ & $\begin{array}{c}\mathrm{pH} \\
\text { Çalışma } \\
\text { Aralığ }\end{array}$ \\
\hline $\mathrm{RBV}-1^{*}$ & 4 & 29 & 67 & - & 29,8 & $10^{-2}-10^{-5}$ & $8,7 \times 10^{-6}$ & $8-10$ & $6-7$ \\
\hline RBV-2 & 8 & 27 & 65 & & 23,0 & $10^{-2}-10^{-4}$ & $4,6 \times 10^{-5}$ & $8-10$ & $6-7$ \\
\hline RBV-3 & 4 & 29 & - & 67 & 21,7 & $10^{-2}-10^{-4}$ & $3,3 \times 10^{-4}$ & $8-10$ & $6-7$ \\
\hline RBV-4 & 8 & 27 & - & 65 & 19,4 & $10^{-2}-5 \times 10^{-4}$ & $3,1 \times 10^{-4}$ & $8-10$ & $6-7$ \\
\hline $\mathrm{RBV}^{* *}$ & 7 & 31 & - & 61 & 45,6 & $10^{-4}-10^{-6}$ & $1 \times 10^{-7}$ & 180 & $3-5$ \\
\hline
\end{tabular}

*Aynı sensörün MIP yerine NIP içeren tipi de hazırlanmıştır.

**:Literatür çalışmasıdır ve membran bileşiminde ek olarak \%1 grafen oksit içermektedir (Jian-Wen ve ark, 2017).

Şekil 2.'de MIP ve ve NIP ile hazırlanan sensörlerin sensörün potansiyel-zaman grafikleri karşılaştırmalı olarak verilmiştir. Grafikler incelendiğinde MIP ile hazırlanan sensörün beklenildiği gibi NIP ile hazırlanan sensöre göre performansının çok iyi (doğrusal çalışma aralığı oldukça geniş 
ve eğimi yüksek) olduğu görülmektedir. MIP sensörün cevabının daha yüksek olmasının nedeni; iyonofor görevi gören polimerik yapı içerisinde ribavirine özgü kalıpların (kavite) mevcut olması ve çözeltide bulunan ribavirin moleküllerinin bu boşluklar ile etkileşiminin fazla olmasıdır.

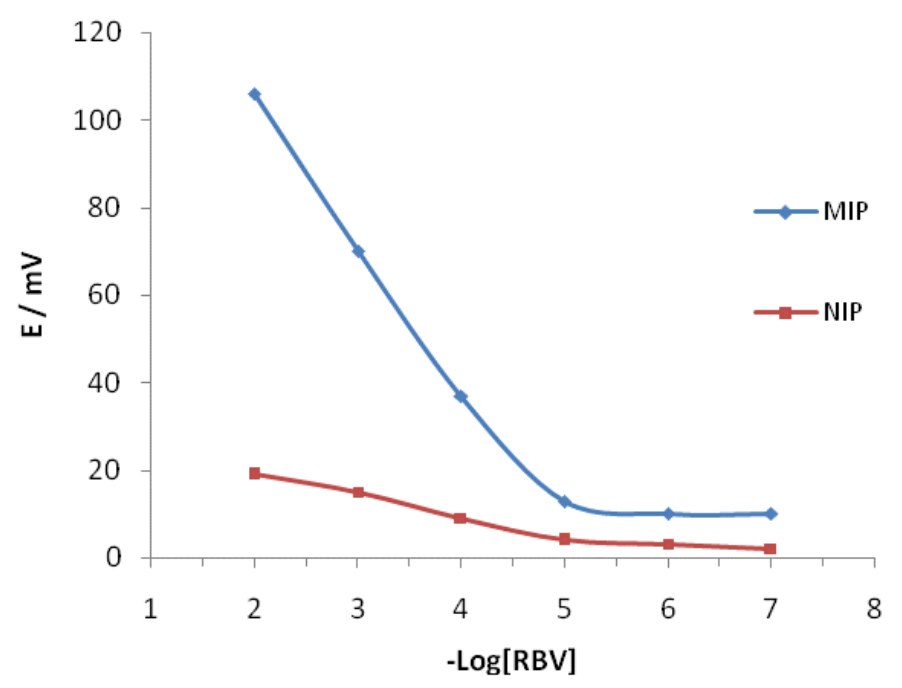

Şekil 2. MIP ve NIP ile hazırlamış sensörlere ait potansiyel-zaman grafikleri.

Şekil 3.'de $1 \times 10^{-5}-1 \times 10^{-2} \mathrm{M}$ derişim aralığındaki ribavirinin ara çözeltilerine sırasıyla daldırılan RBV-1 sensörün ait potansiyometrik davranışı ve Şekil 4.'de kalibrasyon grafiği görülmektedir. Kalibrasyon grafiğinden geliştirilen RBV-seçici sensörün çok sayıda ara çözeltiye karşıda oldukça doğrusal davrandığı söylenebilir.

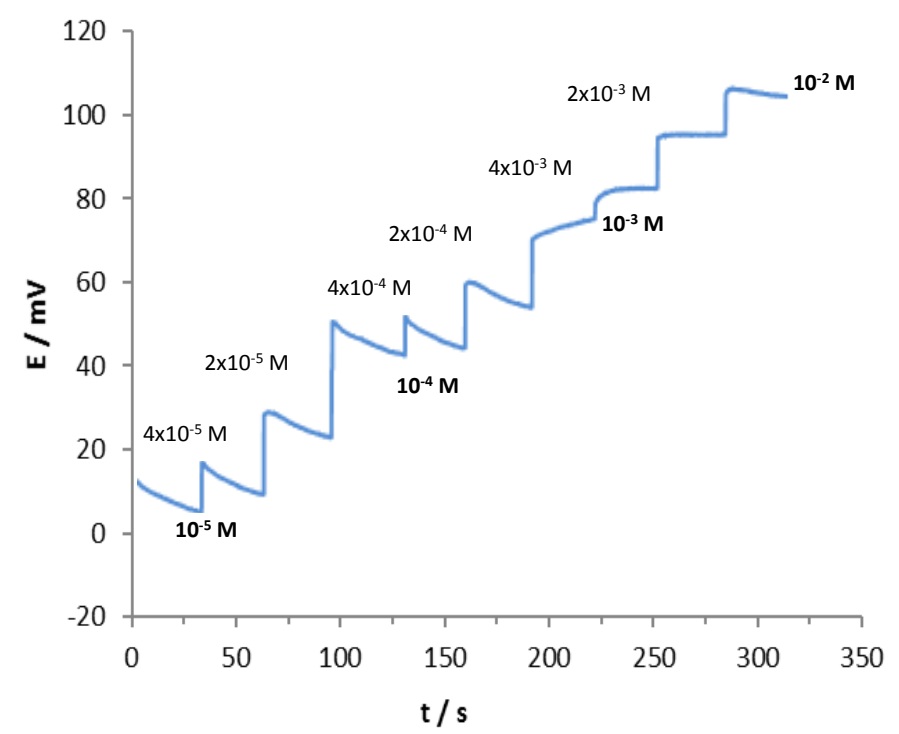

Şekil 3. RBV-seçici sensöre ait potansiyel-zaman grafiği (ara çözeltiler için) 


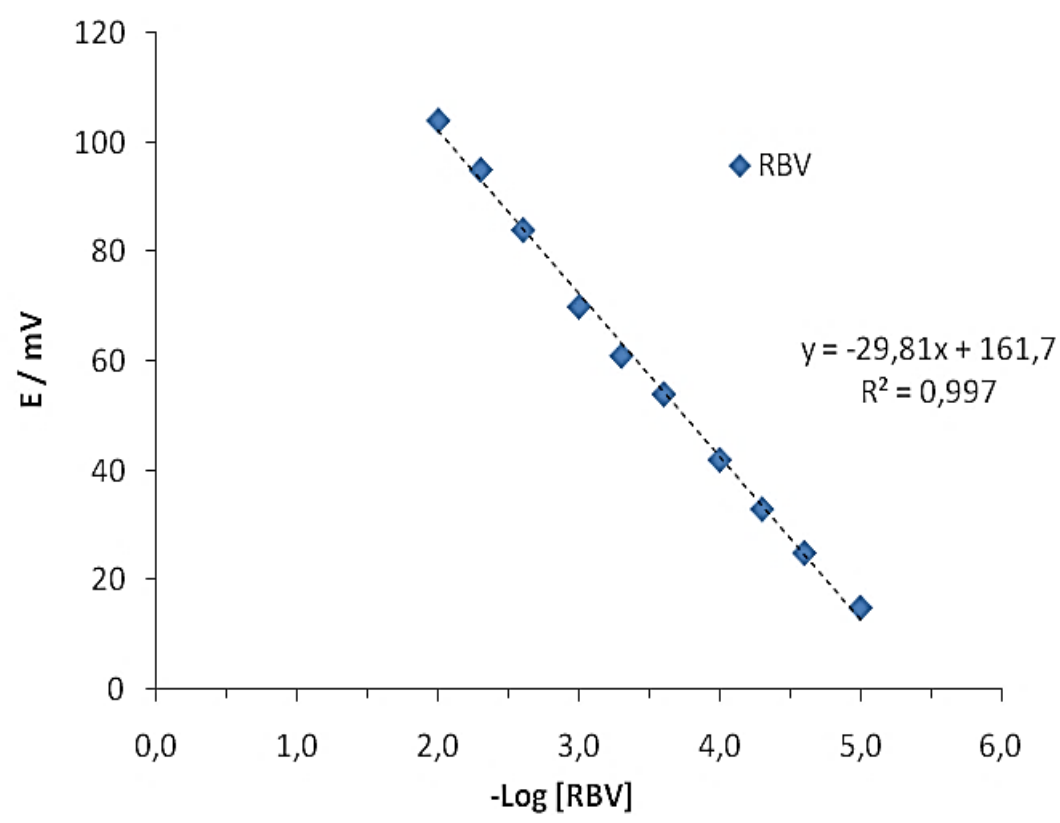

Şekil 4. RBV-seçici sensöre ait ara çözelti kalibrasyon grafiği.

\section{pH Çalışma Aralı̆̆ı}

Sensörlerin çalışabileceği $\mathrm{pH}$ aralığının tespit edilmesi önem arzetmektedir. $\mathrm{Bu}$ amaçla içerisinde ribavirin derişimi $10^{-3} \mathrm{M}$ olarak sabit tutulan tampon çözeltiler $(\mathrm{pH}=3-9$ aralığında) kullanıldı. Ribavirin-seçici sensörlerin pH'ya karşı potansiyometrik davranışları grafiksel olarak Şekil 5.'de görülmektedir. Grafikten sensörün nötral bölgeye yakın $(\mathrm{pH}=6-7)$ ve çok dar bir aralıkta pH değişiminden etkilenmediği ancak diğer pH değerlerinde oldukça etkilendiği görülmektedir. $\mathrm{Bu}$ durumun ribavirin yapısında bulunan amin gruplarının proton ilgisinden kaynaklanabileceği söylenebilir.

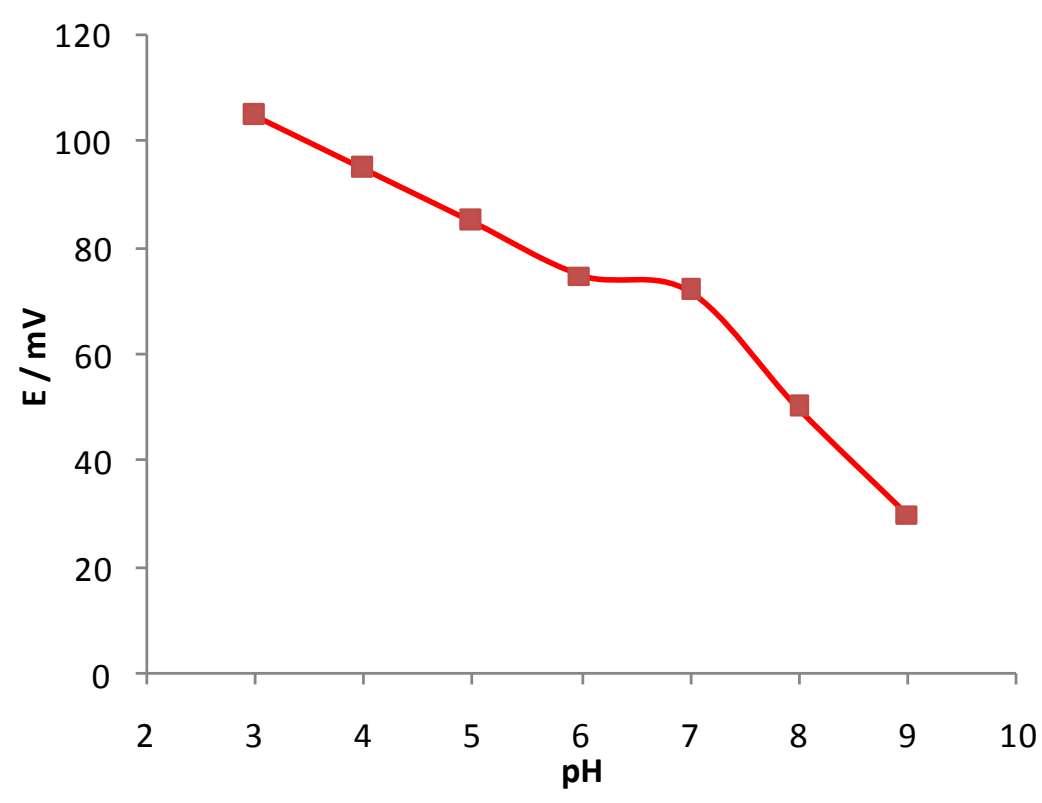

Şekil 5. RBV-seçici sensöre ait $\mathrm{pH}$ çalışma aralığı grafiği. 


\section{Tekrarlanabilirlik Çalışması}

$10^{-3}-10^{-2}-10^{-3} \mathrm{M}$ derişim aralığındaki standart ribavirin çözeltilerine (düşük derişimden yüksek derişime doğru ve tekrar düşük derişime dönüş) sırasıyla daldırılan ve 10 kez tekrarlanan ribavirinseçici sensörün potansiyometrik verileri Tablo 2.'de görülmektedir.

Tablo 2. Ribavirin-seçici sensöre ait ortalama ve standart sapma değerleri.

\begin{tabular}{cccccccccccc}
\hline \multirow{2}{*}{$\begin{array}{c}\text { Derişim } \\
(\mathbf{m o l} / \mathbf{L})\end{array}$} & $\mathbf{1}$ & $\mathbf{2}$ & $\mathbf{3}$ & $\mathbf{4}$ & $\mathbf{5}$ & $\mathbf{6}$ & $\mathbf{7}$ & $\mathbf{8}$ & $\mathbf{9}$ & $\mathbf{1 0}$ & $*$ \\
\cline { 2 - 10 } & $\mathbf{x} \pm \mathbf{s}$ \\
\hline $\mathbf{1 0}^{-2}$ & 104,4 & 104,0 & 104,4 & 104,5 & 104,3 & 104,5 & 105,2 & 104,4 & 105,3 & 103,4 & $104,4 \pm 0,5$ \\
\hline $\mathbf{1 0}^{-3}$ & 70,6 & 70,5 & 70,4 & 70,3 & 69,6 & 70,3 & 70,1 & 69,5 & 69,4 & 71,2 & $70,2 \pm 0,6$ \\
\hline
\end{tabular}

${ }^{*} \mathrm{n}=10$ için ortalama değer olup standart sapması ile birlikte verilmiştir.

Elde edilen verilerden geliştirilen sensörün oldukça geniş bir derişim aralığında $\left(\sim 10^{-5}-10^{-2} \mathrm{M}\right)$ doğrusal ve tekrarlanabilir davrandığg, çok düşük ribavirin derişimlerine $\left(\sim 10^{-6} \mathrm{M}\right)$ cevap sergilediği ve çok kısa cevap zamanına ( 10 sn) sahip olduğu görülmektedir. Sensörün tayin sınırının $8,65 \times 10^{-6}$ M ve her logaritmik artışta derişim birimi için ortalama potansiyel değişiminin 29,8 $\pm 2,1 \mathrm{mV}$ olduğu hesaplanmıştır. Sensörün kullanım ömrü ortam şartlarına bağlı olarak yaklaşık 4-6 haftadır.

\section{Ticari İlaç Numunelerinin Ribavirin İçeriğinin Belirlenmesi}

Ribavirin içeriği belirlenecek ilaç numuneleri (her tablet yaklaşık 200 mg ribavirin içermekte) suda çözülerek 0,45 mikronluk filtrelerden süzülmüş, sonrasında potansiyometrik analize hazır hale getirilmiştir. Standart ribavirin çözeltileri için elde edilen potansiyel değerleri kullanılarak kalibrasyon grafikleri ve bunlara ait doğru denklemleri oluşturulmuştur. Standart ekleme yöntemi (Skoog ve ark., 2004) uygulanarak sonuçlar hesaplanmıştır (Tablo 3.). Elde edilen veriler beyan edilen ticari değerler ile kıyaslandığında RBV-seçici sensörün yaklaşık \% 7-13 bağıl hata aralığında çalıştığını sonucuna varılmıştır.

Tablo 3. Ticari ilaç numunelerinin potansiyometrik tayin sonuçları.

\begin{tabular}{|c|c|c|c|c|}
\hline \multirow{2}{*}{ Numune No } & \multirow{2}{*}{ İlaç } & Potansiyometrik Metot & Ambalaj Değeri & \multirow{2}{*}{ \% Bağıl Hata } \\
\hline & & $(\mathrm{mg} / \text { tablet })^{*}$ & (mg/tablet) & \\
\hline 1 & A & $222 \pm 5$ & 200 & 11,0 \\
\hline 2 & B & $225 \pm 8$ & 200 & 12,5 \\
\hline 3 & $\mathrm{C}$ & $215 \pm 4$ & 200 & 7,5 \\
\hline
\end{tabular}

\footnotetext{
* Değerler $\mathrm{n}=3$ için ortalama ribavirin miktarları standart sapması ile birlikte verilmiştir.
} 


\section{Sonuçlar ve Öneriler}

Süspansiyon yöntemi ile sentezlenen ribavirin baskılanmış polimerlerin seçici materyal olarak kullanıldığı ribavirin-seçici potansiyometrik mikrosensör geliştirilmiştir. Geliştirilen mikrosensör kullanılarak bazı ticari ilaçların ribavirin içerikleri başarıyla belirlenmiştir. Ribavirinin farklı polimerizasyon yöntemleriyle baskılanması ve performansı daha iyi mikrosensör tiplerinin geliştirilmesi üzerine çalışmalarımız devam edecektir.

\section{Teșekkür}

$\mathrm{Bu}$ çalışmanın potansiyel ölçümlerinde kullanılan çok kanallı potansiyometrenin dizayn edilmesinde FEN-BAP-A-160512-36 ve bazı kimyasalların temin edilmesinde FEN-BAP- A250414-48 numaralı projelerle destek olan Giresun Üniversitesi BAP Koordinatörlüğüne teşekkürlerimizi sunarız.

\section{Kaynaklar}

Alarfaj, N. A., and El-Toh, M. F., (2012). Determination of the anti-viral drug Ribavirin in dosage forms via micelle-enhanced spectrofluorimetric method. Luminescence, 28(2), 190-194.

Bochenska, M. (1998). Structural aspects of host molecules acting as ionophores in ion-selective electrodes. Journal of Molecular Structure. 450, 107-115.

Breadmore, M. C., Theurillat, R., and Thormann, W., (2004). Determination of ribavirin in human serum and plasma by capillary electrophoresis. Electrophoresis, 25, 1615-1622.

Isildak, I., Yolcu, M., Isildak, O., Demirel, N., Topal, G., and Hosgoren, H. (2003). All-solid-state PVC membrane $\mathrm{Ag}^{+}$-selective electrodes based on diaza-18-crown-6 compounds. Microchimica Acta. 144, 177-181.

IUPAC Analytical Chemistry Division, Commission on Electroanalytical Chemistry, (1994). Recomendations for nomen-clature of Ion-selective Electrodes, Pure and Applied Chemistry, 66, 2527-2536.

Javanbakht, M., Fard, S. E., Mohammadi, A., Abdouss, M., Ganjali, M. R., Norouzi, P., and Safaraliee, L., (2008). Molecularly imprinted polymer based potentiometric sensor for the determination of hydroxyzine in tablets and biological fluids. Analytica Chimica Acta. 612(1), 65-74.

Jian-Wen, L., Shou-Lian, W., Na-Na, C., (2017). A Ribavirin Potentiometric Sensor Based on Molecularly Imprinted Polymers Doped with Graphene Oxide Film. Chinese Journal of Analytical Chemistry, 45(7), 1031-1037.

Karabörk, M. (2007). Iyon Baskllamaya Dayanan Katı-Faz Ekstraksiyonu, Doktara Tezi, Anadolu Üniversitesi, Fen Bilimleri Enstitüsü, Eskişehir.

Lijke H., Alffenaar, J. W. C., Kok, W. T., Greijdanus, B., and Uges, D. R. A., (2012). Determination of ribavirin in human serum using liquid chromatography tandem mass spectrometry. Talanta, 88, 385390.

Scott, L. J., Perry, C. M., (2002). Interferon-alpha-2b plus ribavirin: a review of its use in the management of chronic hepatitis C. Drugs, 62(3), 507-556.

Skoog, D. A., West, D. M., Holler, F. J., and Crouch, S. R., (2004). Fundamentals of analytical chemistry. US: Brooks/Cole Thomson Learning Inc. Press.

$\mathrm{Xu}, \mathrm{L} ., \mathrm{Xu}, \mathrm{Z}$., (2012). Molecularly imprinted polymer based on multiwalled carbon nanotubes for ribavirin recognition, Journal of Polymer Research. 19, 9942. 
Yarman, A. and Scheller, F.W., (2014). The First Electrochemical MIP Sensor for Tamoxifen. Sensors. 14(5), $7647-7654$.

Yolcu, M. (2008). Seçici Kondüktometrik ve Potansiyometrik Mikro-Sensörlerin ve Hareketli Ölçüm Sistemlerinin Çevre Örneklerine Uygulanması, Doktora Tezi, Ondokuz Mayıs Üniversitesi, Fen Bilimleri Enstitüsü, Samsun.

Yolcu, Z. (2011). Vinil Grubu İçeren Cu(II) ve Zn(II) Komplekslerinin Sentezlenmesi ve Bazı Polimerlerinin Metal Iyon Baskılama Özelliklerinin Araştırılması, Doktora Tezi, Ondokuz Mayıs Üniversitesi, Fen Bilimleri Enstitüsü, Samsun.

Zironi, E., Gazzotti, T., Lugoboni, B., Barbarossa, A., Scagliarini, A., and Pagliuca, G., (2011). Development of a rapid LC-MS/MS method for ribavirin determination in rat brain. Journal of Pharmaceutical and Biomedical Analysis, 54(4), 889-92. 